Studia Anglica Posnaniensia 46/3, 2011(2010)

doi: 10.2478/v10121-010-0003-8

\title{
MOTEN IN CANTERBURY TALES: THE SPEAKER'S EXPRESSION OF THE SELF
}

KATARZYNA STADNIK

Maria Curie-Skłodowska University, Lublin

\begin{abstract}
In the paper, we posit the centrality of the speaker in language. In so doing, we refer to the fact that language users may select particular linguistic expressions to encode their understanding of a given situation. This observation alludes to the concept of subjectivity in linguistics, and evokes the notion of modality, concerned, broadly speaking, with the speaker's attitude to the proposition. In English, linguistic devices used to signal the varying degrees of the speaker's commitment towards the proposition include modal verbs. Historically, they can be claimed to have developed from less to more subjective meanings, as in the case of the modal verb must. Its epistemic meaning is believed to have evolved from its deontic sense in the Middle English (ME) period. While some authors argue that, at this stage of its development, epistemic must was less, rather than more subjective, we test a different supposition. In our view, epistemic must occurring in generalized necessity statements might acquire a more subjective reading. Specifically, it seems possible to argue that, by personalizing generalized truths, the speaker tinges them with more subjective overtones. We exemplify the claim using the occurrences of ME *moten 'must' in Canterbury Tales.
\end{abstract}

\section{Introduction}

In the article, we test and exemplify the possibility of presenting modality as one type of self-expression. In that, we follow Łozowski (2008: 129): "what brings an individual to modality is his/her drive and need to verbalize personal judgements and opinions with regard to verbalized judgements and opinions of others. As this can be done by exploring available linguistic resources ... and employing available experiential strategies ..., the net effect is a never-ending progression of virtual projections, all by means of turning ... constructions into more and more abstract entities". 
The concept of modality is by far one of the most intricate notions, which hardly lends itself to a neat characterisation. ${ }^{1}$ In the words of Warner (1993: 17), "the notion of modality is potentially a very wide one, as are its possible realizations".

Although we might be tempted to reduce modality to "the grammaticization of speakers' (subjective) attitudes and opinions" (Bybee et al. 1994: 176), it seems clear that "modality notions range far beyond what is included in this definition". If so, it is only natural that "there is little agreement on exactly how to define modality" (Traugott - Dasher 2002: 105). Some linguists take an extreme view, and question the idea that modality can be regarded as an independent category at all (Mortelmans 2007: 869).

It seems that "the task ... of defining 'modality' is closely related to and, in fact, dependent on what types of modality one is prepared to distinguish" (Lozowski 2008: 97). Thus, for the purposes of our diachronic investigation concerning the development of the Middle English modal verb *moten 'must', we follow Saeed (2009: 138) in claiming that "modality is a cover term for devices which allow speakers to express varying degrees of commitment to, or belief in, a proposition". The possible linguistic strategies used to "mark the variations of commitment towards the assertion" include the employment of modal verbs (Saeed 2009: 139).

In the paper we follow Saeed's distinction of modality into two basic types: (i) deontic and (ii) epistemic. ${ }^{3}$ Broadly speaking, "deontic modality ... involves

Thus, for instance, Fischer (2007: 178) avoids defining the concept, discussing "the general characteristics of modality systems" instead.

2 Nuyts (2005: 1) concurs, saying that "the notion ... has been used in different ways in the literature".

3 Lyons (1995: 335) recognizes three types of modality: aletheutic [or alethic], epistemic and deontic, acknowledging "the logic roots of modality research" (Lozowski 2008: 95). Since aletheutic modality is "the modality of the necessary truth of propositions" (Coates 1983: 18), it is "by definition truth-functional" (Lyons 1995: 329). This is why, with respect to modality "in the everyday use of natural languages", Lyons claims that "modality is more likely to be either epistemic or deontic than aletheutic" (Lyons 1995: 329.). Coates (1983: 18) distinguishes two modality types: (i) epistemic, and (ii) root. The latter term is used to avoid the arbitrary subdivision of the root category into subtypes, indicating the "essential unity of the root modals" (Coates 1983: 21). Sweetser (1990: 152) also prefers the term root to deontic, concurring that the former has a broader sense. In his revised, second edition of Mood and modality (1986), Palmer (2001) mentions two general modality types, that of propositional modality, subsuming epistemic and evidential modality, both concerned with "the speaker's attitude to the truth-value or factual status of the proposition" (Palmer 2001: 8), and that of event modality, embracing deontic and dynamic modalities, related to "events that are not actualized ..., but are merely potential" (Palmer 2001: 8). In more recent work on modality, Nuyts (2005: 2) points to "three notions traditionally most commonly mentioned as the modal categories - dynamic, deontic, and epistemic", whereby the dynamic type "is traditionally characterized as an ascription of a capacity to the subject- 
obligation or compulsion" (Traugott - Dasher 2002: 106), and most often "derives from some source or cause" (Lyons 1977, 2: 823). Epistemic modality "is largely concerned with knowledge and belief (as opposed to fact)" (Traugott Dasher 2002: 106). Epistemic expressions are thus used "to express the speaker's degree of commitment (short of complete) to the truth of the proposition" (Traugott - Dasher 2002: 106).

However, as we read in Lyons (1995: 329), both deontic and epistemic modality "may be either objective or subjective", which requires providing a more detailed account of modality types. That is to say, instead of the twofold deontic-epistemic distinction, we need a more comprehensive view of both deontic and epistemic modality, including their objective and subjective aspects. With this in mind, we follow Lyons' (1995: 331) claim that, with objective modality, "speakers (more generally, locutionary agents) may be ... reporting, as neutral observers, the existence of this or that state of affairs". ${ }^{4}$ In contrast, with subjective modality, the speakers "may be expressing either their own beliefs and attitudes or their own will and authority" (Lyons 1995: 331).

Naturally, the above remarks concerning subjective and objective aspects of modality evoke the concept of subjectivity. ${ }^{6}$ For Cuyckens et al. (2010: 1), the notion, in general sense, refers to "the centrality of the speaker in language".

participant of the clause" (Nuyts 2005: 3). The same tripartite division of modality can be found in Palmer (2003: 7). Lyons (1995: 335) provides a final comment on the possibility to distinguish various modality types, admitting that, except the already mentioned, "other kinds of modality ... have also been recognised in recent years by both linguists and logicians", but "so far there is no consensus among either linguists or logicians on the establishment of a comprehensive framework which is both theoretically coherent and empirically satisfactory".

$4 \quad$ Although Coates (1983: 18) argues that "objective epistemic modality ... is clearly related to alethic modality", Nuyts (2005: 8) makes it clear that "the notion is close to, yet distinct from, epistemic modality". Alethic modality concerns modes of truth, while epistemic modality concerns modes of knowing (Nuyts 2005: 9).

5 With respect to the division of modality into objective and subjective types, Coates (1983: 18) stresses the fact that "while objective epistemic modality does occur in natural language ..., it is not very common". Her view that "this has been recognised by linguists whose definitions have emphasised the subjectivity of epistemic modality" seems to be confirmed by Lyons' (1995: 330) observation that "subjective modality is much more common than objective modality in most everyday uses of language; and objective epistemic modality, in particular, is very rare". More to the point, Palmer (1986: 16) argues that subjectivity is "an essential criterion for modality".

6 Portner (2009: 108) acknowledges that "[t]he concept of subjectivity was introduced by Benveniste (1971) and applied in detail to English modals by Lyons (1977)".

7 As Cuyckens et al. (2010: 1) caution, "the notion of 'subjectivity' is not a straightforward matter, as it has several uses and interpretations". In their view, it "subsumes various ways in which an expression may involve speaker-reference" (Cuyckens et al. 2010: 8). Following De Smet and Verstraete (2006: 348), the general notion of subjectivity "is inherent in language use and is independent of the semantics of a particular expression". 
From this perspective, language is seen as "an expression ... of perceiving, feeling, speaking subjects" (Finegan 1995: 2; original emphasis). If so, "all language is thus subjective by definition" (Cuyckens et al. 2010: 9).

The notion of subjectivity "can be theorized in many ways" (Traugott 2010: 29), "in current linguistic theorizing, the most prominent exponents of subjectivity [being] probably Langacker and Traugott" (Athanasiadou et al. 2006: 2). Both authors "have extended the concept of subjectivity to subjectification according to the premises of their respective theoretical frameworks" (Athanasiadou et al. 2006: 2).

In the case of Langacker (e.g. 2003, 2008), the process of modalization is an example of the attenuation of subject control, i.e. subjectification. Although Narrog (2010: 389) agrees that "the suggestion that the attenuation of the role of the grammatical subject is an important aspect of the semantic development of English modal verbs is intuitively plausible", he nevertheless cautions that Langacker "does not support it with historical data".

While Langacker (2008: 77) understands subjectivity in terms of cognitive construal, Traugott (1999: 188) makes it clear that, in her view, the "expressions of subjectivity ... are expressions the prime semantic or pragmatic meaning of which is to index speaker attitude or viewpoint" (Traugott 2010: 32). She defines subjectification as "the semasiological process whereby linguistic expressions acquire subjective meaning" (Cuyckens et al. 2010: 4). That is to say, they "tend to be increasingly based in the SP/W's subjective belief state or attitude to what is being said and how it is being said"(Traugott 2003: 125).

As Traugott (1999: 188) argues, subjectification is a "diachronic phenomenon only", her research being based on "linguistically highly contextualized and always naturally occurring" data. Thus, for the purposes of our diachronic investigation, our take on subjectivity and subjectification in the domain of modal verbs is Traugottian. ${ }^{9}$

$8 \quad$ As Traugott (2010: 32) argues, "at issue is the development of semantic (coded) polysemies that have to be learned with subjective ... meanings". She hypothesizes that "most new semantic developments emerge as polysemies, pragmatic to begin with, then semantic" (Traugott 2010: 32). Such "subjectified polysemies may index evaluation of ... attitude towards the truth of a proposition" (Traugott 2010: 32). The mechanism that "allows inferences and meanings supplied by the context to become part of the meaning of a grammatical morpheme or construction" is pragmatic strengthening (Bybee 2010: 171). Bybee claims that "pragmatic inference allows new meaning to become associated with a construction" (Bybee 2010: 171).

9 With respect to the notion of subjectivity in the English modal verbs, we rely on Traugott's (1989: 36) observation that "it is not clear whether truly objective modality exists, especially in the epistemic domain". Therefore, we follow the author in employing the terms “'less' and 'more' subjective modality, or 'weakly' and 'strongly' subjective", hinting at the 
Therefore, in our discussion of the development of must we follow Traugott and Dasher (2005: 132) in distinguishing three stages of its evolution. Must i.e. OE mot-, instantiates the premodal "ability" meaning, expressing both ability and permission (Traugott - Dasher 2005: 122). The latter meaning can still be found in the ME period, although its use is restricted primarily to "formulae for prayers, blessings, curses, and oaths, e.g. so mot I then "so may I thrive"" (Traugott - Dasher 2005: 123). More specifically, in LOE and ME, the sense of permission conveyed by mot- came to be replaced by may<magan "have the physical ability" (Traugott - Dasher 2005: 123).

The next stage features must $_{2}$, which arose especially in EME along with the old ability and permission meanings, in that mot- began to acquire a new obligation sense (Traugott - Dasher 2005: 123). The authors hypothesize that the new deontic meaning emerged in the context of participant-external uses (Traugott - Dasher 2005: 125.). Thus, "the development of strong obligation must from weaker permission" resulted in the deontic polysemy (Traugott - Dasher 2005: 126).

The third stage is the epistemic must. One of the contexts which promoted the rise of must $_{3}$ is claimed to be that of general statements, which could be constructed as both general deontic necessity and epistemic (Traugott - Dasher 2005: 127). Goossens (2000: 161) views this indeterminacy between the "participant-external" and "general objective use" as "the first stepping stone" to epistemic must. ${ }^{10}$

It is this generic context that we take to be of critical importance for our analysis. Traugott and Dasher (2005: 129) argue that such examples of epistemic necessity conveyed by must, which appear by the middle of the ME period, are "relatively objective". ${ }^{11}$ However, we claim that it is possible to consider some of such occurrences of the modal verb in the generic context as more strongly subjective.

Importantly, for Goossens (2000: 163), such uses of must are "inferential" rather than "fully epistemic" (Traugott - Dasher 2002: 129). This inferable necessity entails inference-making, which may contribute to the increase in sub-

notion of gradience in subjectivity (Traugott 1989: 36.). As Traugott (2005: 115) herself admits, "[s]ince modality is by definition somewhat subjective, subjectification in historical modality involves shifts from less to more subjectively construed obligation, epistemic attitude, etc.".

10 Goossens (2000: 161) points to the fact that "this usage constitutes a subset of the participant-external type .... On the other hand, ... there is an epistemic/inferential ingredient", in that ME must in such examples is often "accompanied by the adverb nedes necessarily". More specifically, Traugott and Dasher (2005: 128) claim that "it is reasonable to believe that nedes played a key role in the semanticization of epistemic must". What seems to be the case is that, as McMahon (1994: 188) argues, the epistemic meaning of nedes was "transferred from the adverb to the verb".

11 With regard to footnote 6 , we take it to mean 'weakly' subjective. 
jectivity, and provides a link with the modality of conclusion expressed by must, used to infer the inevitability of things.

Since, as shown above, epistemic must derives from its originally deontic, that is obligation meaning, there arises a question what contexts promote inference-making, and, thus, whether inferable necessity might be considered to encourage the appearance of the modal's subjective meanings.

It might thus seem reasonable to seek an inferential ingredient in indeterminate statements where both deontic and epistemic readings are possible. Such constructions include the already mentioned generalised necessity statements conveying universal truths, where the general nature of authority invites inference-making. Indeed, as modal occurrences, they may be concerned with expressing the speaker's propositional attitude. This means that inferences are made by the speaker, which implies that the speaker becomes the source of modality. All in all, generalised necessity statements with a clear speaker-source may be inferential in character due to the presence of the speaker forming their own conclusions.

\section{Analysis}

Taking the above into consideration, we shall thus posit the assumption that the marked presence of the first-person speaker in the generic context may promote the increase in subjectivity of epistemic must. To test and exemplify our supposition, we have gathered a number of examples of ME * moten from the relevant period, using Geoffrey Chaucer's Canterbury Tales ${ }^{12}$. Out of the total number of 228 occurrences of must in The Canterbury Tales, ${ }^{13}$ we have selected ten representative occurrences of must, ${ }^{14}$ exemplifying generalised necessity statements with some inference-making, whereby conclusions are attributable to a first-person speaker. ${ }^{15}$

For the sample source see Benson.

Cf. Glossarial Database Concordance at http://www.courses.fas.harvard.edu/ pitf05/tools/

The total number of must occurrences includes must with the sense of permission, while the majority of occurrences express deontic obligation. Out of this group, over 20 occurrences appear in the generic context with a universal source of authority and generalised subjects, while the eight of them may be claimed to have a personalised dimension, whereby the speaker relates the situation/event they are contemplating to themselves or their experience.

15 Importantly, what supports our view is the following hypothesis posited by Traugott (2010: 58): "it seems likely that shifts in the referent of the subject would generally be relevant to the development of subjective meanings". More specifically, "[s]hifts toward first person subjects are not necessary correlates of or indicators of subjectivity since subjectification may be most apparent precisely where there is no overt subject, first person or otherwise" (Traugott 2010: 58). Crucially, as Scheibman (2002: 167, as quoted in Traugott 2010: 58; the second emphasis added) puts it, "the presence of $I$ does not necessarily subjectify on its own". 
In our view, these occurrences might be said to have a personalised dimension. That is to say, it seems possible to conclude that, in such cases, must conveys not what Traugott and Dasher (2005: 129) call "relatively objective" epistemic meaning, but epistemic meaning which we consider more strongly subjective.

The first instance may be considered a point of departure for the subsequent, more speaker-based modal occurrences of must.

1) He moot be deed, the kyng as shal a page; ... Thanne may I seyn that al this thyng moot deye.

[One must die, whether a king or a page; ... So I can state that all things must die]

(The Knight's Tale, 11. 3030-3034).

This example of generalised necessity entails a universal truth concerning the necessity for all things to come to an end: the first-person speaker says that everything has an end, and, thus, it is reasonable to conclude that, with respect to people, everybody will die. If so, we might expect that the inference extends to the present in that it is inevitable that every day somebody dies. That is to say, the general character of the necessity invites the inference that what must necessarily occur in the future may as well apply to the present situation. In other words, the statement contains a truth which, as such, holds true under any circumstances. This, by implication, means that we may refer it to our present situation. Crucially, since it is the speaker himself who draws the conclusion, he is the source of modality. This makes the universal truth more speaker-based, i.e. more subjective: the statement is a universal truth as acknowledged by the speaker. The modal emerges as epistemic: the necessity for all people to die comes to express the inevitability of death concerning all people. Yet, although we may detect some subjective overtones related to the presence of the speaker, the modal occurrence is contextualised in logical reasoning, which does not permit strongly subjective meanings.

The following example departs from the previous, default case in that must seems to acquire more personalised meanings.

2) A man moot nedes love, ... He may nat fleen it, thogh he sholde be deed ...

[A man must necessarily love, ... He cannot escape it, though he should be dead ...]

(The Knight's Tale, 11. 1169-1170). 
The speaker states that the necessity to love someone refers to people in general. What is more, love is an irresistible affection, a power with which nothing else can match. Yet, although the statement contains a universal truth, it cannot be separated from the speaker: the preceding and following lines of the passage in question, which, for the economy of space, have been omitted, tell us that the speaker himself is in love. Hence we may conclude that the speaker draws certain inferences which, in fact, concern his own situation: his condition constitutes a specific case of the universal truth. The presence of the speaker enables us to consider the generalised necessity statement as anchored in his perspective. We might thus assume that through the context of the speaker's situation the modal occurrence acquires a more subjective tinge when compared to the previous example.

Indeed, the meaning of must becomes increasingly personalised as shown by the subsequent example where the first-person speaker, a servant, is compelled to conclude that he cannot avoid fulfilling his master's will.

3) The lord knew wel that he hym loved and dradde; ... he sayde ... men moote nede unto hire lust obeye ...

[The lord knew he was loved and feared by [the servant]; ... [the servant] said ... when [lords] want something, people must necessarily obey ...]

(The Clerk's Tale, Part III, 11. 523-532).

The modal occurrence appears in the context of logical reasoning whereby the speaker states clearly that he acts under constraint. He says that all servants are bound to satisfy their masters will, so he has no choice but to follow his master's commands. Yet, the context proves helpful once more: the relationship between the servant and his master is defined by love and fear. The servant has always blindly obeyed the master's orders. The general statement concerning the necessity to fulfil masters' will may thus be seen as a mere justification for the servant's actions. From this perspective, it is evident that in the same circumstances somebody else might have drawn a different conclusion. That is to say, the speaker refers the generalised necessity to himself, and the statement undergoes personalisation, expressing what the speakers deems appropriate. If so, we may claim that the source of authority is, in fact, the speaker, who expresses his belief in the truth of the proposition.

In the following example the generalised necessity takes the form of a custom, or, more specifically, particular behaviour expected of widows.

4) Whan that my fourthe housbonde was on beere, I weep algate, As wyves mooten, for it is usage ... 
[When my fourth husband was laid on his bier, I wept for him ... As all wives must, because it's the custom...]

(The Wife of Bath's Prologue, 11. 587-589).

The first-person speaker is a widow talking about her late husband. She says that it is the custom which forces all widows to mourn after their husbands' death. In other words, the necessity is indeed of universal nature due to the force of social constraints. However, since the speaker is first-person, we may reasonably assume that she simply presents her own opinion on the matter. Thus the implicit conclusion is that, if the widows were free from the necessity to obey the social norms, they would not feel sorry at all. In other words, the seemingly generalised statement expresses the speaker's own way of approaching the issue. Therefore, we may conclude that, due to the reference to the speaker's specific situation must seems to acquire a personalised meaning.

The following example is a similar instance of generalised necessity with the exception that the speaker refers the necessity to his present situation.

5) Whoso shal telle a tale after a man, He moot reherce as ny as evere he kan Everich a word ... Plato seith ... The wordes moote be cosyn to the dede.

[When telling a tale told by another man, You must repeat as nearly as you can Each word, ... Plato ... says, 'The word must by necessity correspond to the deed']

(The General Prologue, 11. 731-742).

In the extract, both instances of must exhibit the same first-person speaker, which indicates the possibility of attributing the statements to a specific individual. In sum, the speaker draws attention to the fact that the custom or rule of telling the story with all its details is known to his listeners. That is to say, it is a rule when telling a story to report the events exactly, or risk being inaccurate, or even misleading the listeners. If so, this implies that the speaker has based his judgement on his personal knowledge of certain universal standards of behaviour. In other words, since the obligation applies to everybody, his inference is that he is no exception: he has no choice but to accept the rules, and act accordingly. With the inference based on this knowledge of certain social norms, it might be assumed that the statement is anchored in the speaker's perspective, which makes the modal occurrence personalised.

The idea behind the second occurrence of must where the speaker comments on the necessity for people to practise what they preach is to strengthen the already mentioned necessity to be faithful when repeating a story, making it almost a moral requirement, or a social norm to be obeyed. However, although Plato is referred to as an authority on moral standards, it is the speaker who concludes that since this necessity is of universal nature, it applies to his as 
well. Thus the modal conveys a personalised meaning because it expresses what, considering his own situation, the speaker agrees to find appropriate.

So far, we have demonstrated that the seemingly external necessity is subject to personalization because the speakers relate some universal constraints to their situation. Our next example indicates that the speaker might also personalise a necessity by reference to his own life experience. Since the speaker evidently establishes connections between the universal necessity and his personal experiences, must might be truly subjective.

6) Who may been a fool but if he love? ... But all moot ben assayed, hoot and coold; A man moot ben a fool, or yong or oold I woot it by myself ful yore agon, For in my tyme a servant was I oon.

[Who can be a fool unless he is in love? ... But all must be tried, hot or cold; A man must be a fool, either young or old - I experienced it myself long ago: I was a servant [of love] in my time]

(The Knight's Tale, 11. 1799-1814).

In this example the first-person everything and everybody to undergo trials. Thus it might be inferred that people endure hardship in life. Yet, it does not seem impossible to assume that in fact the speaker draws on his own experience to form a subjective inference concerning the condition of man. If so, the basis for drawing such conclusions seems to be his personal experience. It is used as some soft of evidence that, in the speaker's view, extends from his individual perspective to all relevant cases. That is to say, from the speaker's perspective, based in his life experience, it is inevitable that for people in general life is a test. Through the reference to the speaker's own experience the generalised statement becomes personalised. Naturally, the degree of subjectivity inherent in the statement may change depending on the extent to which we are willing to generalise personal life experiences: we might argue that it is not impossible to find a common denominator for individual experiences in people's lives, yet people are inclined to consider their experiences in life as personal and thus unique.

Finally, the last example of generalised necessity which might be considered a case of strongly personalised, subjective meanings.

7) Mariage is a ful greet sacrement. He which that hath no wyf, I holde hym shent ... So buxom and so vertuous is she, They moste nedes lyve in unitee. [Marriage is a great sacrament. He who has no wife, I consider him ruined, ... So obedient and so virtuous is she, They must necessarily live in unity] 
Contextualised in logical reasoning, the generalised necessity statement expresses the inference made by the speaker that, since marriage offers so many advantages, it is necessary for every secular man to take a wife. At the same time, in the preceding lines, the speaker admits that he believes marriage to be a blessing. In brief, he explicitly states that this is his own opinion. If so, it does not seem unreasonable to conclude that, the generalised necessity statement is not a product of his inference-making. In reality, it is the expression of his own belief in what he considers desirable, or appropriate. Thus the lines preceding the statement simply provide arguments for the case the speaker is making. That is to say, he strongly believes that marriage is good, extending this belief, through the use of the subsequent arguments, to all relevant cases, and turning the statement into a generalised truth. In other words, the statement is, in fact, personalised because it is based entirely on the speaker's belief. As such, the modal occurrence expresses his subjective attitude towards the proposition.

In our analysis, the point of departure for personalised, or more subjective uses of must (i.e. as compared to Traugottian "relatively objective" must) has been the generalised necessity statement where the speaker comments on a necessity of universal nature. In such passages, the speaker refers this necessity to their own situation. The meaning of the modal undergoes personalisation: the necessity comes to be considered from the point of view of the speaker.

Since we situate the process of reasoning in the mind of a particular speaker, specifically, in those cases where the speaker is first person, or otherwise identifiable, we cannot separate such statements from the speaker.

Therefore, the source of modality is only seemingly speaker-external. The inference-making resides in the mind of the speaker, which allows us to anchor the meaning of the modal in the speaker's perspective.

Personalisation means that generalised truths are related to the specific situation of the speaker, which seems to encourage the emergence of more speakerbased meanings of must. The modal may become more subjective because through personalisation the speaker evaluates a given situation, including their own condition, in relation to his life experience, knowledge of the world, or what he believes to be true. This imparts more subjective overtones to a given modal occurrence. Often this personalised meaning is implied, and the marked presence of the first-person speaker makes it inferable. More specifically, what highlights the subjective nature of such must occurrences appears to be the use of the adverb nedes 'necessarily' or 'by necessity', which can be found in almost all of the passages discussed.

It might be thus concluded that the rise of more subjective must may be attributable to the marked presence of the first-person speaker. More specifically, what seems to be at issue is the personalisation of generalised truths. That is to say, the speaker refers to their own situation in terms of the generalised truths, 
which might reflect how the speaker makes sense of his/her experience. This, in turn, adds a more subjective tone to the occurrences of must in the generic context. $^{16}$

In that light, it becomes evident that personalised occurrences of ME *moten in The Canterbury Tales are crucial because they seem to show how personalisation might affect the meaning of the modal, fostering conditions favourable to the development of more subjective epistemic must.

\section{Concluding remarks}

All in all, the selected examples are generalised necessity statements rendered inferable by the speaker. What is common to all of these cases is the fact that, at a glance, necessity seems external, and its source may vary: it might be a social norm, a custom, or a master's will; sometimes the authority remains vague. At first, the statements appear to express objective, universal truths, but in reality they contain an implicit inference that objectivity pertains only to the generalised nature of necessity. That is to say, the fact that the truth applies to all relevant cases.

However, the perception of necessity is filtered through the mind of the speaker. Since it becomes related to the speaker's life experience, his knowledge of the world, of, finally, his attitude towards a particular proposition, the objective truth as such ceases to exist: things become what we make of them. If so, generalised necessity undergoes specification: the speaker's own situation constitutes a specific case of generalised necessity in question. What follows is that the speaker acknowledges the truth first, which subsequently allows him to relate it to his condition. Such personalisation, in turn, seems to allow increasingly subjective meanings of must to emerge.

\section{REFERENCES}

Athanasiadou, Angeliki - Costas Canakis - Bert Cornille

2006 "Introduction", in: Angeliki Athanasiadou et al. (eds.), Subjectification. Various paths to subjectivity. Berlin - New York: Mouton de Gruyter, 1-13.

Athanasiadou, Angeliki - Costas Canakis - Bert Cornille (eds.)

2006 Subjectification. Various paths to subjectivity. Berlin - New York: Mouton de Gruyter.

16 For the economy of space, we have limited our sources to The Canterbury Tales. Crucially, our analysis of similar examples from Troilus and Criseyde seems to confirm that at issue is the speaker's self-expression taking the form of their self-reflection. 
Barcelona, Antonio (ed.)

2000 Metaphor and metonymy at the crossroads: A cognitive perspective. Berlin - New York: Mouton de Gruyter.

Berg, Thomas - Hubert Cuyckens - Rene Dirven - Klaus-Uwe Panther (eds.)

2003 Motivation in language. Studies in honour of Günter Radden. Amsterdam - Philadelphia: John Benjamins Publishing Company.

Blank, Andreas - Peter Koch (eds.)

1999 Historical semantics and cognition. Berlin - New York: Mouton de Gruyter.

Bybee, Joan

2010 Language, usage and cognition. Cambridge: Cambridge University Press.

Bybee, Joan - Revere Perkins - William Pagliuca

1994 The evolution of grammar: Tense, aspect, and modality in the languages of the world. Chicago: The University of Chicago Press.

Coates, Jennifer

1983 The semantics of the modal auxiliaries. London: Croom Helm.

Cuyckens, Hubert - Kristin Davidse - Lieven Vandelanotte

2010 "Introduction", in: Hubert Cuyckens et al. (eds.), Subjectification, intersubjectification and grammaticalization. Berlin - New York: Mouton De Gruyter, 1-26.

Cuyckens, Hubert - Kristin Davidse - Lieven Vandelanotte (eds.)

2010 Subjectification, intersubjectification and grammaticalization. Berlin - New York: Mouton De Gruyter.

Cuyckens, Hubert - Dirk Geeraerts (eds.)

2007 The handbook of cognitive linguistics. Oxford: Oxford University Press.

De Smet, Hendrik - Jean-Christophe Verstraete

2006 "Coming to terms with subjectivity", Cognitive Linguistics 17: 365-392.

Facchinetti, Roberta - Manfred Krug - Frank Palmer (eds.)

2003 Modality in contemporary English. Berlin - New York: Mouton de Gruyter.

Finegan, Edward

1995 "Subjectivity and subjectivisation: An introduction", in: Dieter Stein - Susan Wright (eds.), Subjectivity and subjectivisation. Cambridge: Cambridge University Press, 1-15.

Fischer, Olga

2007 Morphosyntactic change: Functional and formal perspectives. Oxford - New York: Oxford University Press.

Frawley, William - Erin Eschenroeder - Sarah Mills - Thao Nguyen (eds.)

2005 The expression of modality. Berlin - New York: Mouton de Gruyter.

Goossens, Louis

2000 "Patterns of meaning extension, 'parallel chaining', subjectification, and modal shifts", in: Antonio Barcelona (ed.), Metaphor and metonymy at the crossroads: A cognitive perspective. Berlin - New York: Mouton de Gruyter, 149-169.

Hickey, Raymond (ed.)

2003 Motives for language change. Cambridge: Cambridge University Press.

Langacker, Ronald

2003 "Extreme subjectification. English tense and modals", in: Thomas Berg et al. (eds.), Motivation in language. Studies in honour of Günter Radden. Amsterdam - Philadelphia: John Benjamins Publishing Company, 3-26.

2008 Cognitive grammar: A basic introduction. Oxford: Oxford University Press. 

Lyons, John
1977 Semantics. Vol. 2. London - New York: Cambridge University Press.
1995 Linguistic semantics: An introduction. Cambridge: Cambridge University Press. Łozowski, Przemysław
2008 Language as symbol of experience: King Alfred's 'cunnan', 'magan' and 'motan' in a panchronic perspective. Lublin: Wydawnictwo UMCS.
McMahon, April
1994 Understanding language change. Cambridge: Cambridge University Press.
Mortelmans, Tanja
2007 "Modality in Cognitive Linguistics", in: Hubert Cuyckens - Dirk Geeraerts (eds.), The handbook of cognitive linguistics. Oxford: Oxford University Press, 869-889. Narrog, Heiko

2010 "(Inter)subjectification in the domain of modality and mood - Concepts and crosslinguistic realities", in: Hubert Cuyckens et al. (eds.), Subjectification, intersubjectification and grammaticalization, Berlin - New York: Mouton De Gruyter, 385-429.

Nuyts, Jan

2005 "Modality: Overview and linguistic issues", in: William Frawley et al. (eds.), The

Palmer, Frank expression of modality. Berlin - New York: Mouton de Gruyter, 1-23.

2001 Mood and modality. (Second edition). Cambridge: Cambridge University Press.

2003 "Modality in English: Theoretical, descriptive and typological issues", in: Roberta Facchinetti et al. (eds.), Modality in contemporary English. Berlin - New York: Mouton de Gruyter, 1-17.

Portner, Paul

2009 Modality. Oxford: Oxford University Press.

Saeed, John I.

2009 Semantics. (Third edition). Malden: Wiley-Blackwell.

Stein, Dieter - Susan Wright (eds.)

1995 Subjectivity and subjectivisation. Cambridge: Cambridge University Press.

Sweetser, Eve

1990 From etymology to pragmatics. Metaphorical and cultural aspects of semantic structure. Cambridge: Cambridge University Press.

Traugott, Elizabeth

1989 "On the rise of epistemic meanings in English: An example of subjectification in semantic change", Language 65: 31-55.

1999 "The rhetoric of counter-expectation in semantic change: a study in subjectification", in: Andreas Blank - Peter Koch (eds.), Historical semantics and cognition. Berlin New York: Mouton de Gruyter, 177-196.

2003 "From subjectification to intersubjectification", in: Raymond Hickey (ed.), Motives for language change. Cambridge: Cambridge University Press, 124-139.

2005 "Historical aspects of modality", in: William Frawley et al. (eds.), The expression of modality. Berlin - New York: Mouton de Gruyter, 107-129.

2010 “(Inter)subjectivity and (inter)subjectification: A reassessment”, in: Hubert Cuyckens et al. (eds.), Subjectification, intersubjectification and grammaticalization. Berlin New York: Mouton De Gruyter, 29-71.

Traugott, Elizabeth - Richard Dasher

2002 Regularity in semantic change. Cambridge: Cambridge University Press. 
Warner, Anthony

1993 English auxiliaries: Structure and history. Cambridge: Cambridge University Press.

\section{PRIMARY SOURCES}

Benson, Larry (ed.)

1987 The Riverside Chaucer. Third edition based on F. N. Robinson (ed.), The works of Geoffrey Chaucer. Boston: Houghton Miffin. 